\title{
Granulomatous slack skin responds to UVA1 phototherapy
}

\author{
Oberholzer, P A ; Cozzio, A ; Dummer, R ; French, L E ; Hofbauer, G F L
}

\begin{abstract}
Granulomatous slack skin (GSS) is an extremely rare disorder within the group of cutaneous T cell lymphomas (CTCL). Ultraviolet A1 (UVA1) phototherapy has previously been reported to be useful in the treatment of CTCL such as mycosis fungoides. We report a 35-year-old Caucasian male with GSS treated with UVA1 phototherapy starting at $20 \mathrm{~J} / \mathrm{cm}(2)$ UVA1 3 times a week and subsequently increased in increments of $5 \mathrm{~J} / \mathrm{cm}(2)$ to a medium-range dose of $50 \mathrm{~J} / \mathrm{cm}(2)$ per session. The patient underwent a total of 45 sessions with a cumulative dose of $1,495 \mathrm{~J} / \mathrm{cm}(2)$ UVA1 without any adverse events. At the conclusion of UVA1 phototherapy, a decrease in erythema and skin thickness was observed which was most prominent in the periphery of the lesion in the right groin area. A follow-up 12 months after phototherapy showed continued treatment benefit. To our knowledge, this is the first report describing the successful use of UVA1 (340-400 $\mathrm{nm})$ phototherapy in a patient with GSS.
\end{abstract}

DOI: https://doi.org/10.1159/000226135

Posted at the Zurich Open Repository and Archive, University of Zurich

ZORA URL: https://doi.org/10.5167/uzh-29794

Journal Article

Published Version

Originally published at:

Oberholzer, P A; Cozzio, A; Dummer, R; French, L E; Hofbauer, G F L (2009). Granulomatous slack skin responds to UVA1 phototherapy. Dermatology, 219(3):268-271.

DOI: https://doi.org/10.1159/000226135 


\title{
Granulomatous Slack Skin Responds to UVA1 Phototherapy
}

\author{
Patrick A. Oberholzer ${ }^{a-c}$ Antonio Cozzio ${ }^{a}$ Reinhard Dummer ${ }^{a}$ Lars E. French ${ }^{a}$ \\ Günther F.L. Hofbauer ${ }^{a}$ \\ ${ }^{a}$ Department of Dermatology, University Hospital Zurich, Zurich, Switzerland; ${ }^{b}$ Broad Institute of MIT and Harvard, \\ Cambridge, Mass., and 'Department of Medical Oncology, Dana-Farber Cancer Institute, Harvard Medical School, \\ Boston, Mass., USA
}

\section{Key Words}

Granulomatous slack skin · Cutaneous T cell lymphoma $\cdot$ Ultraviolet A1 phototherapy

\begin{abstract}
Granulomatous slack skin (GSS) is an extremely rare disorder within the group of cutaneous T cell lymphomas (CTCL). Ultraviolet A1 (UVA1) phototherapy has previously been reported to be useful in the treatment of CTCL such as mycosis fungoides. We report a 35-year-old Caucasian male with GSS treated with UVA1 phototherapy starting at $20 \mathrm{~J} /$ $\mathrm{cm}^{2}$ UVA1 3 times a week and subsequently increased in increments of $5 \mathrm{~J} / \mathrm{cm}^{2}$ to a medium-range dose of $50 \mathrm{~J} / \mathrm{cm}^{2}$ per session. The patient underwent a total of 45 sessions with a cumulative dose of $1,495 \mathrm{~J} / \mathrm{cm}^{2}$ UVA1 without any adverse events. At the conclusion of UVA1 phototherapy, a decrease in erythema and skin thickness was observed which was most prominent in the periphery of the lesion in the right groin area. A followup 12 months after phototherapy showed continued treatment benefit. To our knowledge, this is the first report describing the successful use of UVA1 (340-400 nm) phototherapy in a patient with GSS.
\end{abstract}

Copyright $\odot 2009$ S. Karger AG, Basel

\section{Introduction}

Granulomatous slack skin (GSS) is an extremely rare disorder within the group of cutaneous T cell lymphomas (CTCL). In the WHO/EORTC classification of 2005, GSS is referred to as a subtype of mycosis fungoides (MF) [1, 2]. GSS is typically located in the groin or/and armpits with red, non-itchy, slack plaques. Histologically it is characterized by a CD4-positive lymphocytic infiltrate gathered around multinuclear giant cells throughout the whole dermis and subcutis accompanied by phagocytosis of elastic fibres [1,3]. GSS and other CTCL types, in particular CD30-positive CTCL, may be associated with Hodgkin's disease [3].

The clinical course consists of an inflammatory stage accompanied by a dense and granulomatous histological infiltrate which induces changes in connective tissue leading to the elastolytic and anetodermic aspect of slack skin from which this disease derives its name. Therapy is targeted at inflammation as well as the changes in connective tissue. Established treatment options for GSS (and CTCL in general) comprise potent local steroids, interferon, retinoids and psoralen plus ultraviolet A (PUVA).
Ultraviolet A1 (UVA1; 340-400 nm) phototherapy was first described in 1981 [4]. It can be administered in low (10-30 $\left.\mathrm{J} / \mathrm{cm}^{2}\right)$, medium $\left(40-70 \mathrm{~J} / \mathrm{cm}^{2}\right)$ or high doses (up to $130 \mathrm{~J} / \mathrm{cm}^{2}$ ). UVA1 has different effects that may contribute to the suppression, or prevention of flares, of a variety of skin diseases, including its ability to induce T lymphocyte apoptosis [5], likely being relevant in the treatment of CTCL. Its use has lately been documented mainly in atopic dermatitis [6-8], localized scleroderma $[9,10]$ and in lichenoid dermatosis [11]. Other diseases responding to UVA1 phototherapy include keloids [12], urticaria pigmentosa [13] and systemic lupus erythematosus [14]. The value of using UVA1 in the treatment of cutaneous lymphomas has also been qualified by several authors [15-18]. To our knowledge, this is the first report describing the successful use of UVA1 phototherapy in GSS.

\section{Case Report}

A 35-year-old Caucasian male (Fitzpatrick skin phototype II) with unremarkable past medical history and without regular medication was referred to our phototherapy unit in the Department of

\section{KARGER}

Fax +4161306 1234 E-Mail karger@karger.ch www.karger.com
(C) 2009 S. Karger AG, Basel

$1018-8665 / 09 / 2193-0268 \$ 26.00 / 0$

Accessible online at:

www.karger.com/drm
Günther Hofbauer, MD

Dermatology Department, University Hospital Zürich

Gloriastrasse 31

CH-8091 Zürich (Switzerland)

Tel. +41 44255 11 11, Fax +41 4425545 49, E-Mail hofbauer@usz.ch 

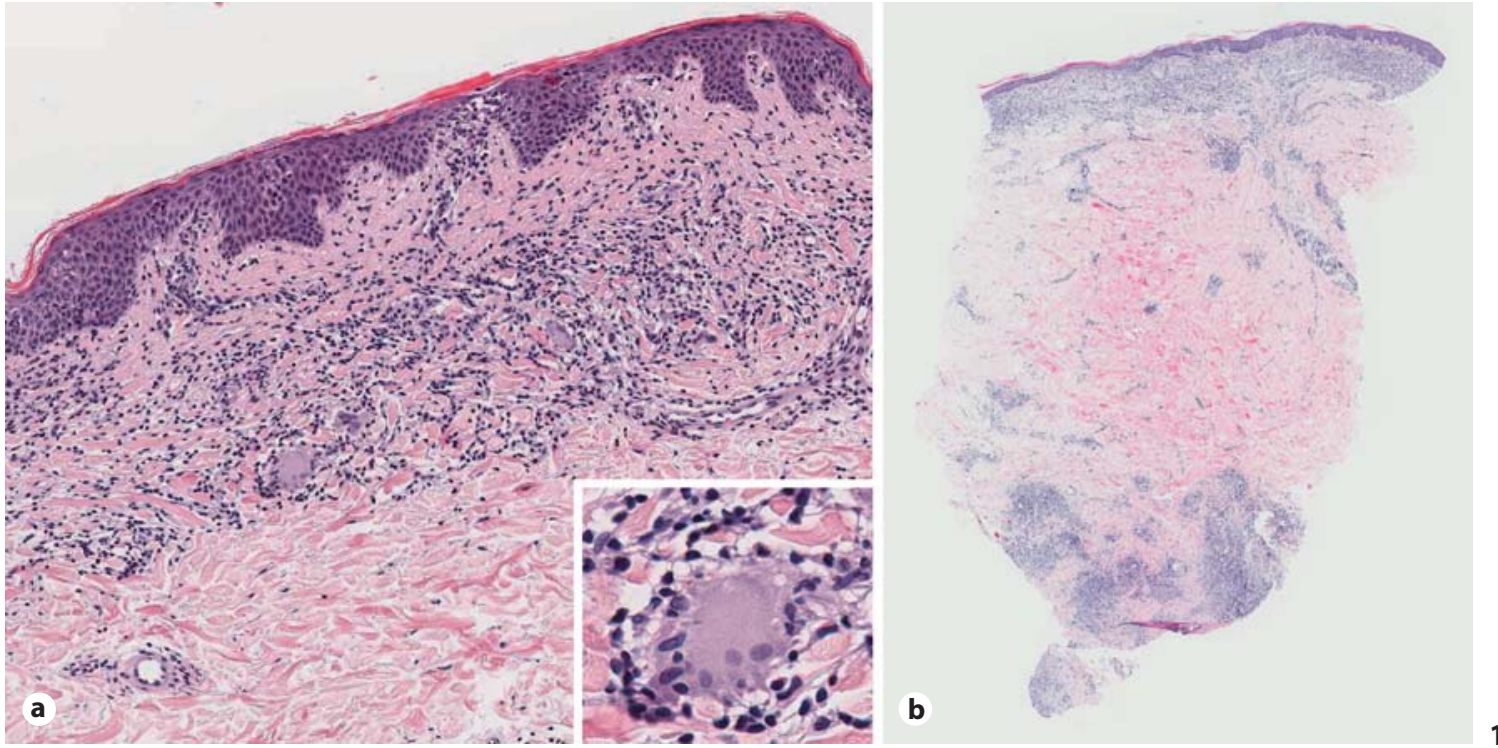

Fig. 1. Skin biopsies taken from GSS before (a) and 12 months after treatment from the UVA1-responding area (b; see fig. 2 for location). Skin biopsies (haematoxylineosin stain) demonstrate orthokeratosis with limited parakeratosis, and little spongiosis. In the upper dermis there appears a subepidermal, focally epidermotropic infiltrate of lymphocytes, mixed single histiocytes and multinucleated giant cells with rosette-like figures. The lymphocytic infiltrate is more pronounced in the pretreatment area of GSS (a), while increased connective tissue in the upper and middermis is more pronounced in the area responding to UVA1 treatment (b). Details of epidermal and dermal GSS involvement before treatment are shown at magnifications of $\times 100$ (a) and $\times 200$ (inset). $\mathbf{b}$ Haematoxylin-eosin stain of UVA1-responsive area depicted at a magnification of $\times 20$.

Fig. 2. Clinical presentation before (lefthand panels) and after 6 months of UVA1 phototherapy (right-hand panels) with a cumulative dose of $1,495 \mathrm{~J} / \mathrm{cm}^{2}$ in frontal (a) and right lateral (b) view. Note improvement of erythema as well as decrease in infiltrate reflected by more prominent slackness (wrinkling) of the skin most pronounced at the top and bottom lateral periphery of the lesion following 6 months of UVA1 phototherapy (right-hand panels). Twelve months after UVA1 treatment, a $4-\mathrm{mm}$ punch biopsy was taken from the UVA1-treatment-responsive area of GSS (b, white circle).
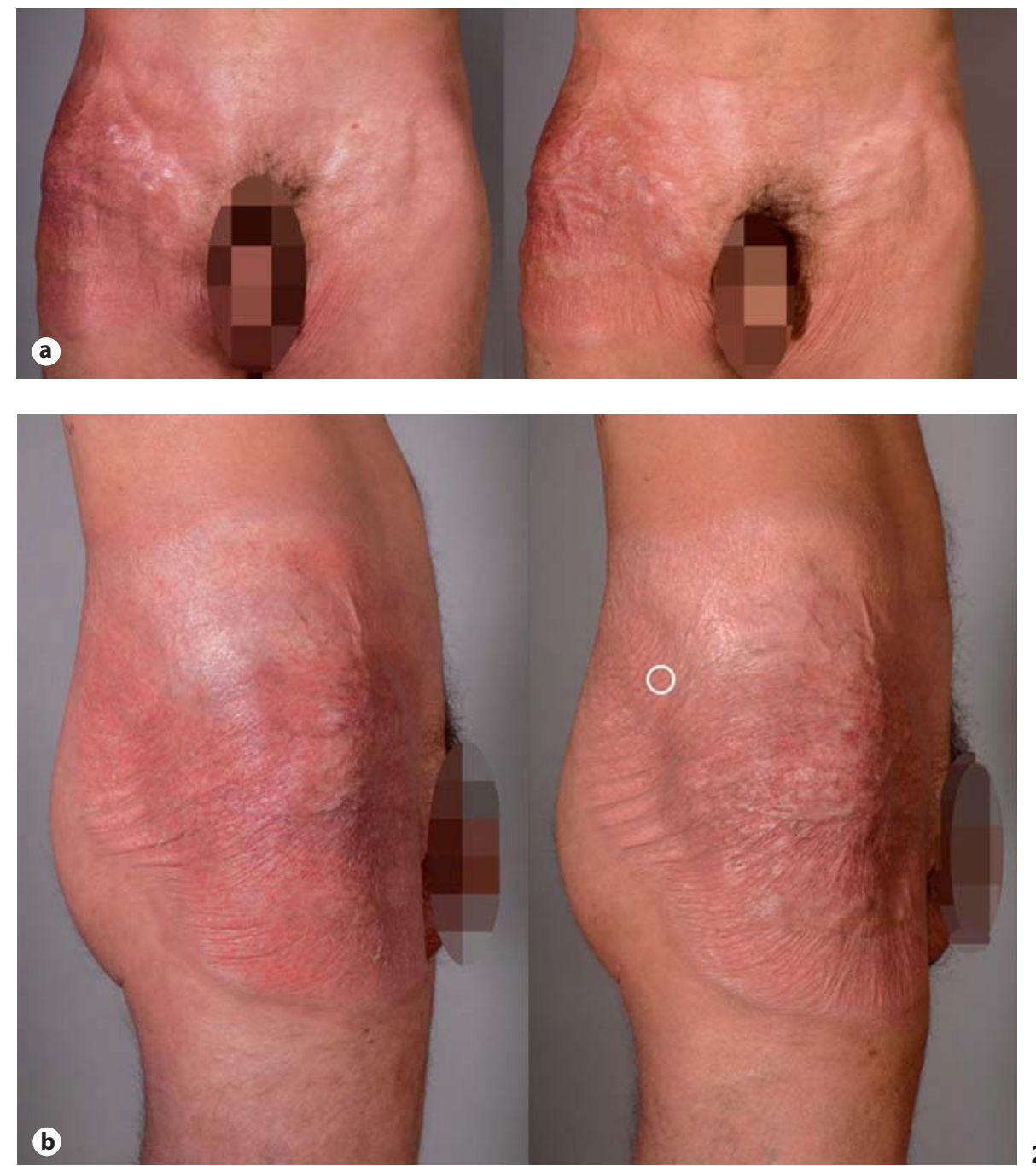
Dermatology with a 13-year history of red, well-demarcated, asymptomatic, slowly growing plaques on his groins. With a 4year delay, the diagnosis of GSS (MF stage IB) was established based on the typical clinical presentation and histology (fig. 1). Complete blood count was repeatedly within normallimits. Ultrasound oflymph nodes and abdomen repeatedly showed stable, enlarged lymph nodes in the right groin without other anomalies, indicating localized disease. Chest X-ray showed no abnormality on several occasions.

After having used topical emollients and potent topical steroids, PUVA therapy in combination with $\alpha$-interferon was initiated because of progressive disease and led to partial remission [19]. Subsequently, treatment was switched to intralesional $\gamma$ interferon-releasing adenovirus injections [20]. Two years before UVA1 phototherapy, the patient had been enrolled in a study protocol combining bexarotene (Targretin ${ }^{\circledR}$ ) and oral suberoylanilide hydroxamic acid (a class of antitumour agents inhibiting histone deacetylase) with resulting mild improvement. Bexarotene induced hyperlipidaemia which occurred 6 months after treatment onset and was therefore discontinued. Suberoylanilide hydroxamic acid was used as monotherapy for another 6 months and was then stopped because of the patient's wish to become father.

After a wash-out period of 1 month, UVA1 therapy was initiated. At the start of UVA1 phototherapy, the patient presented several large, mostly red, partly brownish and whitish, well-demarcated, non-tender, infiltrated plaques spanning the lateral and ventral aspect of his lower trunk slightly extending onto his lower extremities with most pronounced features in the right inguinal area and its lateral continuation (fig. $2 \mathrm{a}$ and b, left-hand panels). Therapy was started at $20 \mathrm{~J} / \mathrm{cm}^{2}$ UVA1 3 times a week and increased in increments of $5 \mathrm{~J} / \mathrm{cm}^{2}$ to a dose of $50 \mathrm{~J} / \mathrm{cm}^{2}$ per session (medium-dose UVA1 phototherapy). A medium-dose regimen was chosen based on findings from the few comparative studies that showed no benefit for highdose over medium-dose UVA1 in atopic dermatitis $[21,22]$ and based on our centre's experience. Incremental doses are part of our standard UVA1 protocol where we initiate therapy without previous determination of the minimal erythema dose. The patient underwent a total of 45 sessions with a cumulative dose of 1,495
$\mathrm{J} / \mathrm{cm}^{2}$ UVA1. No adverse effects were noted during UVA1 phototherapy. At the conclusion of UVA1 phototherapy, a decrease in erythema and a decrease in skin thickness with accompanying more prominent slackness (wrinkling) of the skin probably due to reduction of the inflammatory infiltrate were observed and were most prominent in the periphery of the lesion in the right groin area (fig. $2 a$ and b, righthand panels). A follow-up 12 months after phototherapy showed continued treatment benefit with stable disease under continued use of $0.1 \%$ triamcinolone topically without flare-up of this MF variant. Since $0.1 \%$ triamcinolone has been used continuously topically 3 times/week before, during and after the UVA1 treatment, we suggest that the observed favourable response is rather not due to the topical steroid treatment. Nevertheless, it cannot be entirely excluded that, at least partially, the topical steroid applications contributed to the treatment benefit observed upon UVA1 treatment, especially on a histological level. At this 12-month follow-up, a 4-mm punch biopsy from the UVA1-treatmentresponsive area was taken (histology shown in fig. 1b; biopsy location shown in fig. 2b).

\section{Discussion}

Established treatment options for CTCL in general and GSS in particular comprise potent local steroids, $\alpha$-interferon, retinoids and PUVA, and had all been used in our patient with transient partial remission at best. Phototherapy is a widely used treatment option in MF in general. For patch stage MF, UVB $311 \mathrm{~nm}$ (narrow band) is probably the treatment of choice [23-26]. PUVA is well established for MF and currently mostly used for plaque and tumour stages of MF [27, 28]. Several authors have described a benefit of UVA1 in cutaneous lymphomas [7, 15-17], but to our knowledge no reports of GSS treated with UVA1 have been published. In one case report [15], a case of MF was successfully treated with $60 \mathrm{~J} / \mathrm{cm}^{2}$ UVA 15 times a week for 3 weeks (cumulative UVA dose $900 \mathrm{~J} / \mathrm{cm}^{2}$ ). Plettenberg et al. [16] used UVA1 phototherapy as monotherapy in 3 patients with histologically proven MF (stages IA and IB). For daily whole-body UVA1 irradiations, either a high-dose $(\mathrm{n}=$ 2; $130 \mathrm{~J} / \mathrm{cm}^{2}$ UVA1 per exposure) or medium-dose $\left(\mathrm{n}=1 ; 60 \mathrm{~J} / \mathrm{cm}^{2} \mathrm{UVA} 1\right)$ regimen was used. In all 3 patients (range of cumulative UVA1 dose $960-2,600 \mathrm{~J} / \mathrm{cm}^{2}$ ), skin lesions began to resolve after only a few UVA1 radiation exposures. Complete clearance was observed between 16 and 20 exposures (equals number of exposures), regardless of whether the high- or medium-dose regimen had been employed. In another study [17], $13 \mathrm{MF}$ patients (8 stage IB, 4 stage IIB and 1 stage III) received 100 $\mathrm{J} / \mathrm{cm}^{2}$ UVA1 daily until remission (mean number of exposures 21.9; mean cumulative UVA1 dose 2,148.5 J/cm ${ }^{2}$ ). Eleven patients showed complete clinical and histological responses. Two patients had a partial improvement.

The potential advantages of UVA1 use over other forms of phototherapy include its freedom from systemic or topical pretreatment with psoralens combined with UVA's potential for deeper penetration compared to UVB. UVA1 tolerability is high with few occurrences of treatmentinduced solar erythema, thus not interrupting dose escalation. Acute adverse events have been observed and reported, including (i) erythema (despite this being a less erythematogenic radiation than broad-band UVA or UVB), (ii) brown pigmentation (tanning), (iii) polymorphic light eruption, (iv) itch and (v) reactivation of herpes simplex infection. Little is known about long-term adverse events by treating patients with UVA1, though. The major potential chronic adverse events are photo-aging and skin cancer development, possibly comparable to PUVA which includes the controversial issue of melanoma induction [29].

UVA1 is known to induce collagenase production by fibroblasts. This effect of UVA1 is thought to be beneficial e.g. in systemic sclerosis. GSS is not primarily a sclerosing disorder, rather one with a net loss of functional collagen. Over the course of UVA1 therapy, we observed decreased infiltration of the affected areas and increased wrinkling. Based on clinical impression and histological picture, we assume that UVA1 reduced the inflammatory infiltrate, thus revealing the loss of functional collagen by the underlying disease resulting in increased skin slackness.

In summary, we found UVA1 phototherapy to be a well-tolerated and beneficial treatment option in this patient and would thus like to suggest UVA1 phototherapy as additional treatment modality for GSS. Larger series will be needed to validate this observation. 


\section{References}

1 Burg G, Kempf W, Cozzio A, Feit J, Willemze R, Jaffe SE, Dummer R, Berti E, Cerroni L, Chimenti S, Diaz-Perez JL, Grange F, Harris NL, Kazakov DV, Kerl H, Kurrer M, Knobler R, Meijer CJ, Pimpinelli N, Ralfkiaer E, Russell-Jones R, Sander C, Santucci M, Sterry W, Swerdlow SH, Vermeer MH, Wechsler J, Whittaker S: WHO/EORTC classification of cutaneous lymphomas 2005: histological and molecular aspects. J Cutan Pathol 2005; 32:647-674

2 Kempf W, Michaelis S, Paulli M, Wechsler J, Audring H, Chalid A, Rüdiger T, Willemze R, Meijer CJ, Berti E, Cerroni L, Santucci M, Hallermann C, Berneburg M, Chimenti S, Robson A, Marschalko M, Kazakov DV, Petrella T, Fraitag S, Carlotti A, Courville P, Laeng H, Golling P, Dummer R, Burg G: Granulomatous cutaneous T-cell lymphomas: a multicenter study of the cutaneous lymphoma task histopathology force group of the European Organization for Research and Treatment of Cancer (EORTC). Arch Dermatol 2008;144:1609-1617.

3 LeBoit PE: Granulomatous slack skin. Dermatol Clin 1994;12:375-389.

4 Mutzhas MF, Holzle E, Hofmann C, Plewig $\mathrm{G}$ : A new apparatus with high radiation energy between 320-460 nm: physical description and dermatological applications. J Invest Dermatol 1981;76:42-47.

5 Godar DE: UVA1 radiation triggers two different final apoptotic pathways. J Invest Dermatol 1999;112:3-12.

6 Grabbe J, Welker P, Humke S, Grewe M, Schopf E, Henz BM, Krutmann J: High-dose ultraviolet A1 (UVA1), but not UVA/UVB therapy, decreases IgE-binding cells in lesional skin of patients with atopic eczema. J Invest Dermatol 1996;107:419-422.

7 Krutmann J: Ultraviolet A radiation-induced immunomodulation: molecular and photobiological mechanims. Eur J Dermatol 1998;8:200-202.

8 von Kobyletzki G, Pieck C, Hoffmann K, Freitag M, Altmeyer P: Medium-dose UVA1 cold-light phototherapy in the treatment of severe atopic dermatitis. J Am Acad Dermatol 1999;41:931-937.
9 Kerscher M, Dirschka T, Volkenandt M: Treatment of localised scleroderma by UVA1 phototherapy. Lancet 1995;346:1166.

10 Gruss C, Stucker M, Kobyletzki G, Schreiber D, Altmeyer P, Kerscher M: Low dose UVA1 phototherapy in disabling pansclerotic morphoea of childhood. Br J Dermatol 1997;136: 293-294.

11 Kreuter A, Gambichler T, Avermaete A, Happe M, Bacharach-Buhles M, Hoffmann K, Jansen T, Altmeyer P, von Kobyletzki G: Low-dose ultraviolet A1 phototherapy for extragenital lichen sclerosus: results of a preliminary study. J Am Acad Dermatol 2002; 46:251-255

12 Asawanonda P, Khoo LS, Fitzpatrick TB, Taylor CR: UV-A1 for keloid. Arch Dermatol 1999; 135:348-349.

13 Stege H, Schopf E, Ruzicka T, Krutmann J: High-dose UVA1 for urticaria pigmentosa. Lancet 1996;347:64.

14 Polderman MC, Huizinga TW, Le Cessie S, Pavel S: UVA-1 cold light treatment of SLE: a double blind, placebo controlled crossover trial. Ann Rheum Dis 2001;60:112-115.

15 von Kobyletzki G, Dirschka T, Freitag M, Hoffman K, Altmeyer P: Ultraviolet-A1 phototherapy improves the status of the skin in cutaneous T-cell lymphoma. Br J Dermatol 1999; 140:768-769.

16 Plettenberg H, Stege H, Megahed M, Ruzicka T, Hosokawa Y, Tsuji T, Morita A, Krutmann J: Ultraviolet A1 (340-400 nm) phototherapy for cutaneous T-cell lymphoma. J Am Acad Dermatol 1999;41:47-50.

17 Zane C, Leali C, Airo P, De Panfilis G, Pinton PC: 'High-dose' UVA1 therapy of widespread plaque-type, nodular, and erythrodermic mycosis fungoides. J Am Acad Dermatol 2001;44:629-633.

18 Krutmann J, Stege H, Morita A: UltravioletA1 phototherapy: indications and mode of action; in Krutmann J, Hönigsmann H, Elmets CA, Bergstresser PR (eds): Dermatological Phototherapy and Photodiagnostic Methods. Berlin, Springer, 2001, pp 261276.

19 Schmook T, Hofbauer G, Kempf W, Burg G, Dummer R: Granulomatous slack skin. Partielle Remission unter intraläsionarer Gabe von Interferon-alpha und PUVA. Hautarzt 2001;52:985-988.
20 Dummer R, Hassel JC, Fellenberg F, Eichmuller S, Maier T, Slos P, Acres B, Bleuzen P, Bataille V, Squiban P, Burg G, Urosevic M: Adenovirus-mediated intralesional interferon-gamma gene transfer induces tumor regressions in cutaneous lymphomas. Blood 2004;104:1631-1638.

21 Dittmar HC, Pflieger D, Schopf E, Simon JC: UVA1-Phototherapie: Pilotstudie zur Dosisfindung bei der bei akut exazerbierten atopischen Dermatitis. Hautarzt 2001;52: 423-427.

22 Tzaneva S, Seeber A, Schwaiger M, Honigsmann $\mathrm{H}$, Tanew A: High-dose versus medium-dose UVA1 phototherapy for patients with severe generalized atopic dermatitis. J Am Acad Dermatol 2001;45:503-507.

23 Hofer A, Cerroni L, Kerl H, Wolf P: Narrowband (311-nm) UV-B therapy for small plaque parapsoriasis and early-stage mycosis fungoides. Arch Dermatol 1999;135:13771380.

24 Clark C, Dawe RS, Evans AT, Lowe G, Ferguson J: Narrowband Tl-01 phototherapy for patch-stage mycosis fungoides. Arch Dermatol 2000;136:748-752.

25 Gathers RC, Scherschun L, Malick F, Fivenson DP, Lim HW: Narrowband UVB phototherapy for early-stage mycosis fungoides. J Am Acad Dermatol 2002;47:191-197.

26 Pavlotsky F, Barzilai A, Kasem R, Shpiro D, Trau H: UVB in the management of early stage mycosis fungoides. J Eur Acad Dermatol Venereol 2006;20:565-572.

27 Trautinger F, Knobler R, Willemze R, Peris K, Stadler R, Laroche L, D'Incan M, Ranki A, Pimpinelli N, Ortiz-Romero P, Dummer R, Estrach T, Whittaker S: EORTC consensus recommendations for the treatment of mycosis fungoides/Sézary syndrome. Eur J Cancer 2006;42:1014-1030.

28 Group EGW: Primary cutaneous lymphomas: ESMO clinical recommendations for diagnosis, treatment and follow-up. Ann Oncol 2007; 18:ii61-ii62.

29 Wang SQ, Setlow R, Berwick M, Polsky D, Marghoob AA, Kopf AW, Bart RS: Ultraviolet A and melanoma: a review. J Am Acad Dermatol 2001;44:837-846. 